\title{
Potential regulation of glioma through the induction of apoptosis signaling via Egl-9 family hypoxia-inducible factor 3
}

\author{
KE MAO, CHAO YOU, DING LEI and HENG ZHANG \\ Department of Neurosurgery, West China Hospital of Sichuan University, Chengdu, Sichuan 610041, P.R. China
}

Received February 21, 2015; Accepted January 4, 2016

DOI: $10.3892 / 01.2016 .5492$

\begin{abstract}
Glioma is an aggressive form of brain cancer that occurs following the abnormal proliferation of glial cells. Although glioma cannot spread to other organs, the morbidity and mortality rates of the disease are high, even following surgery, radiotherapy and chemotherapy. The function of Egl-9 family hypoxia-inducible factor $3($ Egln3) in cancer is controversial, and it is debated as to whether Egln 3 positively or negatively regulates tumors. In the present study, a mouse model of low-grade glioma was successfully established. Through the use of immunohistochemical and western blot analyses, it was demonstrated that Egln 3 expression in glioma tissue performed an important role in regulation by amplifying the signals for apoptosis, as determined by an increase in DNA fragments. Furthermore, Egln 3 expression was inhibited by the administration of dimethyloxalylglycine, and the downregulated expression of Egln 3 had marked effects on the regulation of glioma through apoptosis. The present study therefore provides evidence of an association between Egln3 expression and apoptosis in low-grade glioma.
\end{abstract}

\section{Introduction}

The central nervous system is comprised of the brain and the spinal cord, which regulate the majority of bodily functions. Glioma arises as a result of abnormal glial cell proliferation resulting in the formation of an aggressive mass; this occurs most frequently in the brain and less commonly in the spinal cord. Patients with aggressive forms of glioma have an average survival time of 15 months $(1,2)$. Treatment for the disease consists of surgery, in addition to radiation or chemotherapy, and usually only prolongs patient survival for a few more months (3). Early-stage glioma rapidly develops into the advanced stages of disease, due to an invasive nature

Correspondence to: Dr Ke Mao, Department of Neurosurgery, West China Hospital of Sichuan University, 37 Guoxue Lane, Chengdu, Sichuan 610041, P.R. China

E-mail: maoke0987@gmail.com

Key words: glioma, Egl-9 family hypoxia-inducible factor 3, dimethyloxalylglycine, apoptosis, NSG mice and fast growth that is associated with a vigorous pattern of intra-tumor blood vessel formation (4). Other complications of glioma are associated with the stage and treatment of the tumor, with efficacy often depending on the location of the tumor within the brain $(5,6)$. Surgical dissection of the malignancy is not recommended if it has developed within an important structure of the brain. Despite large improvements in microsurgical procedures and the increased availability of advanced chemotherapy, the improvement to patient survival has been controversial. Therefore, detailed investigation is required to establish the underlying mechanisms of glioma pathogenesis and identify novel therapeutic approaches to treat glioma (7).

The Egl-9 family hypoxia-inducible factor (Egln) hydroxylases, including Egln1, Egln2 and Egln3, are proteins that are associated with the oxygen-sensing pathway, and are also involved in the proline hydroxylation of specific targets (8-11). As the hydroxylation reaction requires molecular oxygen (12), any changes in oxygen requirement are monitored through an oxygen sensing pathway. When this pathway is disturbed, it becomes associated with different forms of cancer (13-15). Egln 3 was identified to be an $\alpha$-subunit hydroxylase for hypoxia-inducible factors (Hifs) in an $\mathrm{O}_{2}$-dependent manner, triggering their proteasomal degradation to retract tumor progression (16-18). Additionally, Egln3 exhibits a high affinity for Hif-2 $\alpha$ (19), a protein that regulates genes associated with cell proliferation, angiogenesis and cell metabolism $(16,20,21)$. The upregulation of Hif- $2 \alpha$ is also associated with proapoptotic activity (22). However, the role of Egln hydroxylases in cancer biology is poorly understood, with two varying hypotheses currently presented; one suggesting that they function as tumor suppressors and the other favoring their contribution towards tumor aggressiveness (23-28).

The present study developed a mouse model of glioma and investigated the function of Egln 3 by analyzing its expression in the presence and absence of an Egln 3 inhibitor within the context of apoptosis.

\section{Materials and methods}

Experimental animals. Male 4-month-old NSG mice were purchased from The Jackson Laboratory (Bar Harbor, ME, USA), and were monitored for a week in a host institute West China Hospital of Sichuan University, Chengdu, China) 
under laboratory conditions. The work plan and protocol for the present study were approved by the institutional ethical committee of West China Hospital of Sichuan University (Chengdu, China). Following regular supervision for 1 week, active healthy mice were selected for further procedures. The mice were anesthetized and located in the Lab Standard $^{\mathrm{TM}}$ Stereotaxic Instrument (Stoelting Co., Wood Dale, IL, USA) in a position that allowed easy access for cerebral cortex injection. The mice were then injected intracranially with $1 \mu$ l C6 rat glioma cells (30,000 cells; Sigma-Aldrich, St. Louis, MO, USA), to deliver the cells to the cerebral cortex as previously described (29). Following injection, $1 \mathrm{mg}$ doxycycline was administered to the mice via food for 28 days. The mice that demonstrated glioma symptoms were then sacrificed for further analysis. For Egln 3 suppression, the mice that developed glioma were intraperitoneally injected with dimethyloxalylglycine (DMOG) in a $50 \mu \mathrm{g} / \mathrm{g}$ of body weight concentration, and samples were dissected $72 \mathrm{~h}$ post-DMOG injection. The experiment was designed so that all the mice were scarified on day 30 .

Western blot analysis. The tissue samples from the normal, glioma-induced and Egln3-suppressed mice were dissected and cell lysates were prepared. The cellular proteins were resolved in $12 \%$ sodium dodecyl sulfate-polyacrylamide gel electrophoresis (Sigma-Aldrich) at $60 \mathrm{~V}$ for $5 \mathrm{~h}$, following the previously described protocol (30). Subsequent to membrane blocking, the mice were probed with the Egln3 antibody (catalog no., MA5-16144; Thermo Fisher Scientific, Inc., Waltham, MA, USA) at a dilution of 1:500 or cell death-inducing DFF-like effector A (CAD) antibody (catalog no., C7852; Sigma-Aldrich) at a diluted concentration of 1:5,000. The membranes were then incubated with a rabbit anti-mouse immunoglobulin G (catalog no. ab97043; Abcam, Cambridge, UK) secondary antibody at a dilution of 1:5,000, and was further developed with alkaline phosphatase chromogen (BCIP/NBT; Abcam) obtain the signal.

Immunohistochemistry. For the immunohistochemical analysis of the dissected brain tissues, the samples were initially fixed in $10 \%$ formalin and processed. The paraffin-embedded samples were sliced into $6-\mu \mathrm{m}$ sections and mounted onto glass slides. Following deparaffinization with xylene, the samples were hydrated and incubated with freshly prepared $10 \% \mathrm{H}_{2} \mathrm{O}_{2}$ and $10 \%$ methanol in $1 \mathrm{X}$ phosphate-buffered saline (PBS) for $30 \mathrm{~min}$. Following the PBS wash, the tissue sections were incubated with $0.1 \%$ trypsin in $0.1 \% \mathrm{CaCl}_{2}$ at $37^{\circ} \mathrm{C}$ for $10 \mathrm{~min}$. Subsequently, the sections were incubated at $4^{\circ} \mathrm{C}$ with the primary anti-Egln 3 antibody overnight. Following 3 extensive washes with 1X PBS, the samples were incubated with the suitable secondary antibody (dilution, 1:5,000) for $45 \mathrm{~min}$ at room temperature. Finally, subsequent to washing the sections, the primary antibody was detected using the DAB Substrate kit (Abcam). For the visualization of individual cells, the samples were counter-stained with Ehrlich's hematoxylin (Thermo Fisher Scientific, Inc.).

Terminal deoxynucleotidyl transferase dUTP nick-end labeling (TUNEL) assay. Apoptotic cells exhibit characteristic DNA fragments that are identified using TUNEL assay (31).
The end labeling of DNA fragments was conducted by incorporating 5-bromo-2'-deoxyuridine (Brdu), a thymidine analogue, to the 3 '-ends of the DNA strands. The incorporated Brdu in the apoptotic cells was then identified using the monoclonal mouse anti-all Brdu antibody (catalog no., 05-633; EMD Millipore, Billerica, MA, USA) following staining with the DAB Substrate kit (Abcam).

\section{Results}

Effective initiation of glioma in mice. The mice that were injected with the rat glioma cells, as aforementioned, were scarified on day 30 , and the glioma tissue was bisected. The control and the dissected glioma tissue were then subjected to histological analysis aiming to understand the nature of the cell arrangement and identify any abnormalities. The histological brain sectioning of the control and glioma tissue are presented in Fig. 1A and B. By comparing the normal and glioma-induced brain tissue, well-distinguishable features were observed. The normal brain was characterized by a uniform cellular pattern (Fig. 1A), whereas a proliferative mass of cells with wide variation among samples was observed in glioma tissue (Fig. 1B).

Role of Egln3 in glioma tissue. In order to investigate the function of Egln 3 in the regulation of glioma growth, a mouse model system was successfully developed with early-stage glioma (Fig. 1B). The normal and glioma tissues were subjected to immunohistochemical analysis to study the apoptosis signal (determined by the brown color produced by the DAB Substrate kit), in addition to assess the association between Egln3 and apoptosis signals (Fig. 2). It was observed, during the initial stages of glioma, that the host exhibited increased expression of Egln3 (Fig. 2E), which acted as a resistance mechanism to regulate glioma, when compared with the normal tissue, which demonstrated lower expression (Fig. 2D). Additional evidence of Egln3 expression came from the increased apoptotic signals observed in the glioma tissue (Fig. 2B) when compared with the controls (Fig. 2A and D).

To analyze the regulative role of Egln3 in early-stage glioma, the Egln3 inhibitor DMOG was used to investigate the apoptosis signal response. The apoptosis signal was measured by the intensity of the brown staining. As presented in Fig. 2F, the inhibitor effectively suppressed Egln 3 expression, and was associated with a poor apoptotic signal and a higher proliferative mass of cells (Fig. 2C). The results confirm that Egln3 positively regulates early-stage glioma by triggering apoptotic signals in abnormal cells.

Validation of the results using western blotting. Western blot analysis was used to evaluate the expression of Egln 3 and the apoptotic signals (assessed in the normal brain and glioma tissue) based on the observed intensity of anti-CAD bands, and also to cross-check the results obtained from immunohistochemistry. The results from western blotting using the anti-Egln 3 and anti-CAD antibodies are presented in Fig. 3. Upregulation of the apoptotic signal with increasing expression of Egln3 was observed, and in the presence of the Egln3 inhibitor, there was a marked difference in the expression pattern of the apoptotic signal and Egln3. 
A

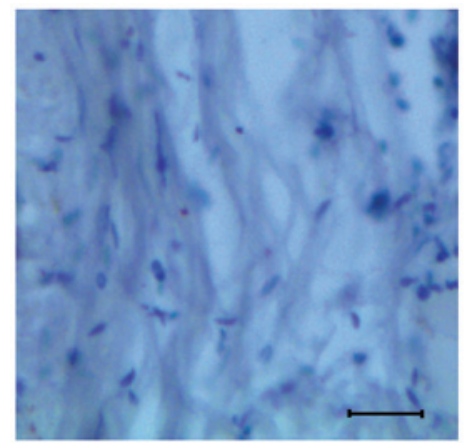

B

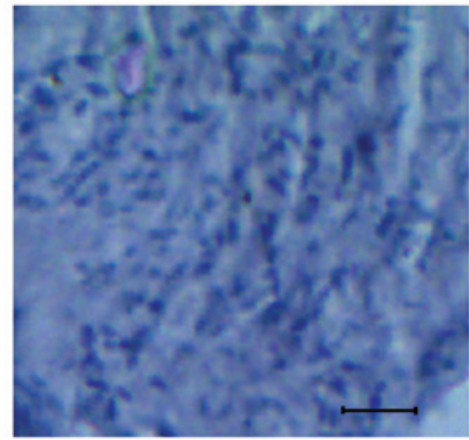

Figure 1. Histological analysis of the normal and glioma brain tissues. (A) Histological section of the brain of a normal mouse exhibiting a uniform arrangement of cells. (B) Histological section of dissected tissue of a glioma-induced mouse exhibiting a higher proliferative mass of cells compared to the normal mouse section. Scale, $100 \mu \mathrm{m}$.

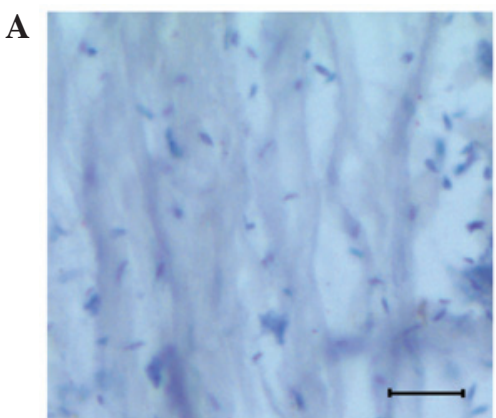

D

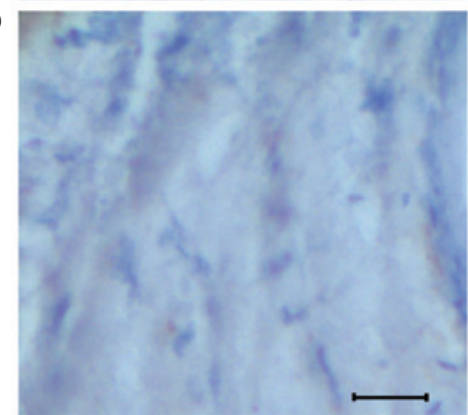

B

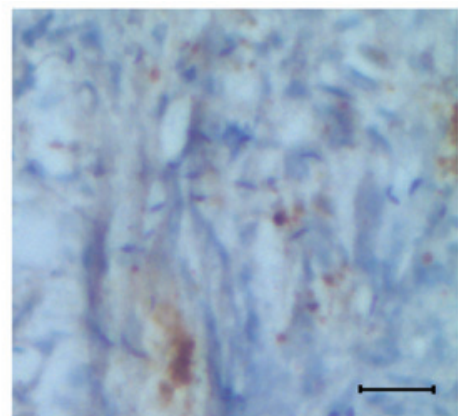

$\mathbf{E}$

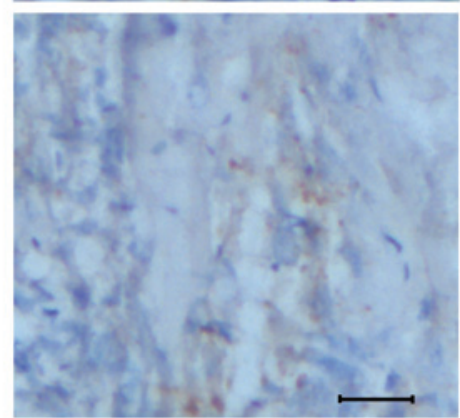

C

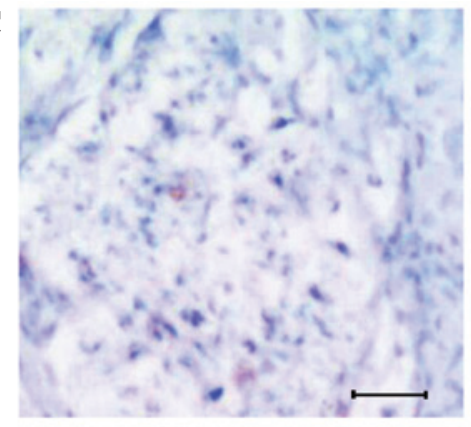

$\mathbf{F}$

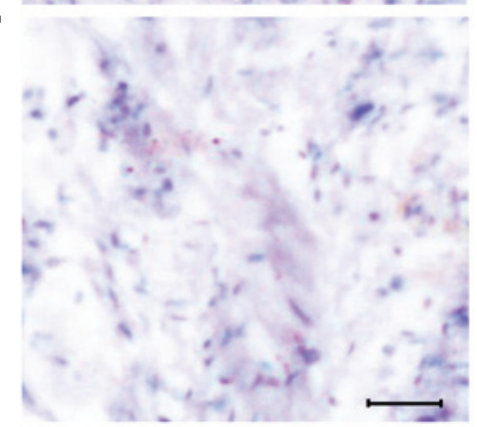

Figure 2. Immunohistochemical variation observed between the normal and glioma tissues of mice. (A) Normal brain tissue of mice demonstrating a poor apoptotic signal. (B) Apoptotic signals in the glioma tissue. (C) Poor apoptotic signals in a DMOG-treated glioma mouse. (D) Normal brain tissue demonstrating reduced Egln 3 expression. (E) Glioma tissue demonstrating increased expression of Egln 3 protein. (F) Suppressed expression of Egln3 protein in the DMOG-treated glioma tissue. Scale, $100 \mu \mathrm{m}$. DMOG, dimethyloxalylglycine.

\begin{tabular}{cccccc} 
& CAD & & \multicolumn{3}{c}{ Egln3 } \\
\hline 1 & 2 & 3 & 4 & 5 & 6
\end{tabular}

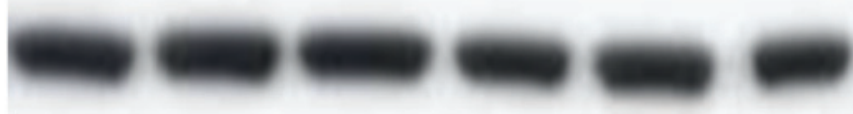

Actin

Figure 3. Egln3 and apoptosis-specific CAD protein expression in the normal and glioma tissue. Lanes 1, 2 and 3 (CAD antibody) indicate the expression of apoptosis-specific CAD protein in the cell lysate of the normal, glioma and Egln3-suppressed glioma mouse tissue. Lanes 4, 5 and 6 indicate the expression of the Egln3 protein in the cell lysate of the normal, glioma and Egln3-suppressed glioma mouse tissue. The apoptotic signals were observed to be higher in the glioma tissue (lane 2) when compared with the normal brain tissue (lane 1) and Egln3-suppressed glioma mice tissue (lane 3). Similarly, Egln3 also exhibited a similar expression profile with increased expression in the glioma tissue when compared with the control and Egln3-suppressed glioma mice. The comparative analysis indicates the links between Egln3 and apoptotic protein expression. $\beta$-actin was used as a loading control. Egln3, Egl-9 family hypoxia-inducible factor 3; CAD, cell death-inducing DFF-like effector A. 


\section{Discussion}

The Egln 3 protein is unregulated in numerous types of human cancer, including pancreatic cancer (32) and glioblastoma (27). The function of $\operatorname{Eg} \ln 3$ is dependent on prolyl hydroxylase activity through which it hydroxylates a number of targets, including Hif- $2 \alpha$ (19) and other $\alpha$ subunits of Hif, larger subunits of RNA polymerase II, pyruvate kinase M2 and $\beta 2$-adrenergic receptors $(11,14,33-36)$. In addition to the prolyl hydroxylase-dependent activity of Egln3, studies have reported the hydroxylase-independent activity of $E g \ln 3$ in regulating the nuclear factor- $\kappa \mathrm{B}$ pathway (37). However, the function of $E g \ln 3$ in carcinogenesis and its biological function have yet to be fully elucidated. At present, the role of $\operatorname{Eg} \ln 3$ in cancer is under debate, with one theory suggesting that it may function as a tumor suppressor, whilst another proposes that it may promote tumor aggressiveness (23-28).

In the present study, an association was observed between Egln 3 expression and apoptosis. A glioma mouse model was successfully developed through the injection of rat glioma cells, which are easily identifiable during histological analysis, into a sample of mice. The dose of rat glioma cells that were injected into the mice was reduced from the standard dose of 50,000 to 30,000 glioma cells $/ \mu 1$ so that slow-growing glioma could form prior to day 30 (29). Reliable data was obtained from immunohistochemical analysis and demonstrated that Egln3 expression in glioma is associated with apoptotic signals. Furthermore, it was also observed that the Egln 3 inhibitor caused a marked decrease in the apoptotic signaling of the glioma tissue. Analysis of the results indicated that the Egln 3 suppression contributed to a poor apoptotic signal and reduced regulation of the glioma, therefore resulting in a higher proliferative cell mass. The data obtained was cross-checked by western blot analysis, which demonstrated consistent results.

In conclusion, the present study successfully developed a mouse model of the initial stage of low-grade glioma at day 30 post-injection. Using this model system, the role of the Egln 3 protein in glioma tissue was studied, and it was observed that Egln 3 expression in glioma is associated with positive regulation through the induction of apoptosis. The continued investigation into this pathological condition may improve our understanding of the mechanisms underlying glioma and may assist with the development of novel therapeutics required to treat patients with this disease.

\section{Acknowledgements}

The authors would like to thank the Institutional Review Board Approval Committee and Ethical Committee (West China Hospital of Sichuan University, Chengdu, China) for the successful completion of this project.

\section{References}

1. Stupp R, Mason WP, van den Bent MJ, Weller M, Fisher B, Taphoorn MJ, Belanger $\mathrm{K}$, Brandes AA, Marosi C, Bogdahn U, et al; European Organisation for Research and Treatment of Cancer Brain Tumor and Radiotherapy Groups; National Cancer Institute of Canada Clinical Trials Group: Radiotherapy plus concomitant and adjuvant temozolomide for glioblastoma. N Engl J Med 352: 987-996, 2005
2. Wen PY and Kesari S: Malignant gliomas in adults. N Engl J Med 359: 492-507, 2008.

3. Cuddapah VA, Robel S, Watkins S and Sontheimer H: A neurocentric perspective on glioma invasion. Nat Rev Neurosci 15: 455-465, 2014.

4. Louis DN, Ohgaki H, Wiestler OD, Cavenee WK, Burger PC, Jouvet A, Scheithauer BW and Kleihues P: The 2007 WHO classification of tumours of the central nervous system. Acta Neuropathol 114: 97-109, 2007

5. Nieder C, Grosu AL, Astner S and Molls M: Treatment of unresectable glioblastoma multiforme. Anticancer Res 25 (6C): 4605-4610, 2005.

6. Stupp R, Pavlidis N and Jelic S; ESMO Guidelines Task Force: ESMO Minimum Clinical Recommendations for diagnosis, treatment and follow-up of malignant glioma. Ann Oncol 16 (Suppl 1): i64-i65, 2005

7. Huse JT and Holland EC: Targeting brain cancer: Advances in the molecular pathology of malignant glioma and medulloblastoma. Nat Rev Cancer 10: 319-331, 2010.

8. Epstein AC, Gleadle JM, McNeill LA, Hewitson KS, O'Rourke J, Mole DR, Mukherji M, Metzen E, Wilson MI, Dhanda A, et al: C. elegans EGL-9 and mammalian homologs define a family of dioxygenases that regulate HIF by prolyl hydroxylation. Cell 107: 43-54, 2001.

9. Ivan M, Haberberger T, Gervasi DC, Michelson KS, Günzler V, Kondo K, Yang H, Sorokina I, Conaway RC, Conaway JW and Kaelin WG Jr: Biochemical purification and pharmacological inhibition of a mammalian prolyl hydroxylase acting on hypoxia-inducible factor. Proc Natl Acad Sci USA 99: $13459-13464,2002$.

10. Kivirikko KI and Myllyharju J: Prolyl 4-hydroxylases and their protein disulfide isomerase subunit. Matrix Biol 16: 357-368, 1998.

11. Bruick RK and McKnight SL: A conserved family of prolyl-4-hydroxylases that modify HIF. Science 294: 1337-1340, 2001.

12. McNeill LA, Hewitson KS, Gleadle JM, Horsfall LE, Oldham NJ, Maxwell PH, Pugh CW, Ratcliffe PJ and Schofield CJ: The use of dioxygen by HIF prolyl hydroxylase (PHD1). Bioorg Med Chem Lett 12: 1547-1550, 2002.

13. Maxwell PH, Wiesener MS, Chang G-W, Clifford SC, Vaux EC, Cockman ME, Wykoff CC, Pugh CW, Maher ER and Ratcliffe PJ: The tumour suppressor protein VHL targets hypoxia-inducible factors for oxygen-dependent proteolysis. Nature 399: 271-275, 1999.

14. Ivan M, Kondo K, Yang H, Kim W, Valiando J, Ohh M, Salic A, Asara JM, Lane WS and Kaelin WG Jr: HIFalpha targeted for VHL-mediated destruction by proline hydroxylation: Implications for O2 sensing. Science 292: 464-468, 2001.

15. Gordan JD and Simon MC: Hypoxia-inducible factors: Central regulators of the tumor phenotype. Curr Opin Genet Dev 17: 71-77, 2007

16. Keith B and Simon MC: Hypoxia-inducible factors, stem cells, and cancer. Cell 129: 465-472, 2007.

17. Kaelin WG Jr: The von Hippel-Lindau tumour suppressor protein: $\mathrm{O}_{2}$ sensing and cancer. Nat Rev Cancer 8: 865-873, 2008.

18. Semenza GL: Angiogenesis in ischemic and neoplastic disorders. Annu Rev Med 54: 17-28, 2003.

19. Appelhoff RJ, Tian Y-M, Raval RR, Turley H, Harris AL, Pugh CW, Ratcliffe PJ and Gleadle JM: Differential function of the prolyl hydroxylases PHD1, PHD2, and PHD3 in the regulation of hypoxia-inducible factor. J Biol Chem 279: 38458-38465, 2004.

20. Rankin EB, Rha J, Unger TL, Wu CH, Shutt HP, Johnson RS, Simon MC, Keith B and Haase VH: Hypoxia-inducible factor-2 regulates vascular tumorigenesis in mice. Oncogene 27: 5354-5358, 2008

21. Ryan HE, Lo J and Johnson RS: HIF-1 alpha is required for solid tumor formation and embryonic vascularization. EMBO J 17: 3005-3015, 1998.

22. Lipscomb EA, Sarmiere PD, Crowder RJ and Freeman RS: Expression of the SM-20 gene promotes death in nerve growth factor-dependent sympathetic neurons. J Neurochem 73: 429-432, 1999.

23. Chan DA, Kawahara TL, Sutphin PD, Chang HY, Chi JT and Giaccia AJ: Tumor vasculature is regulated by PHD2-mediated angiogenesis and bone marrow-derived cell recruitment. Cancer Cell 15: 527-538, 2009.

24. Chan DA and Giaccia AJ: PHD2 in tumour angiogenesis. Br J Cancer 103: 1-5, 2010. 
25. Erez N, Milyavsky M, Eilam R, Shats I, Goldfinger N and Rotter V: Expression of prolyl-hydroxylase-1 (PHD1/EGLN2) suppresses hypoxia inducible factor-1alpha activation and inhibits tumor growth. Cancer Res 63: 8777-8783, 2003.

26. Hatzimichael E, Dasoula A, Shah R, Syed N, Papoudou-Bai A Coley HM, Dranitsaris G, Bourantas KL, Stebbing J and Crook T: The prolyl-hydroxylase EGLN3 and not EGLN1 is inactivated by methylation in plasma cell neoplasia. Eur J Haematol 84: 47-51, 2010.

27. Henze AT, Riedel J, Diem T, Wenner J, Flamme I, Pouyseggur J, Plate KH and Acker T: Prolyl hydroxylases 2 and 3 act in gliomas as protective negative feedback regulators of hypoxia-inducible factors. Cancer Res 70: 357-366, 2010.

28. Mazzone M, Dettori D, Leite de Oliveira R, Loges S, Schmidt T, Jonckx B, Tian YM, Lanahan AA, Pollard P, Ruiz de Almodovar C, et al: Heterozygous deficiency of PHD2 restores tumor oxygenation and inhibits metastasis via endothelial normalization. Cell 136: 839-851, 2009.

29. Li Z, Bao S, Wu Q, Wang H, Eyler C, Sathornsumetee S, Shi Q, Cao Y, Lathia J, McLendon RE, et al: Hypoxia-inducible factors regulate tumorigenic capacity of glioma stem cells. Cancer Cell 15: 501-513, 2009.

30. Hamidouche Z, Haÿ E, Vaudin P, Charbord P, Schüle R, Marie PJ and Fromigué O: FHL2 mediates dexamethasone-induced mesenchymal cell differentiation into osteoblasts by activating Wnt $/ \beta$-catenin signaling-dependent Runx 2 expression. FASEB J 22: 3813-3822, 2008.
31. Fulda S and Pervaiz S: Apoptosis signaling in cancer stem cells. Int J Biochem Cell Biol 42: 31-38, 2010.

32. Su Y,Loos M, Giese N, Hines OJ, Diebold I, Görlach A, Metzen E, Pastorekova S, Friess H and Büchler P: PHD3 regulates differentiation, tumour growth and angiogenesis in pancreatic cancer. Br J Cancer 103: 1571-1579, 2010.

33. Kovalenko A, Chable-Bessia C, Cantarella G, Israël A, Wallach D and Courtois G: The tumour suppressor CYLD negatively regulates NF-kappaB signalling by deubiquitination. Nature 424: 801-805, 2003.

34. Jaakkola P, Mole DR, Tian Y-M, Wilson MI, Gielbert J, Gaskell SJ, von Kriegsheim A, Hebestreit HF, Mukherji M, Schofield CJ, et al: Targeting of HIF-alpha to the von Hippel-Lindau ubiquitylation complex by $\mathrm{O}_{2}$-regulated prolyl hydroxylation. Science 292: 468-472, 2001.

35. Xie L, Xiao K, Whalen EJ, Forrester MT, Freeman RS, Fong G, Gygi SP, Lefkowitz RJ and Stamler JS: Oxygen-regulated $\beta(2)$-adrenergic receptor hydroxylation by EGLN3 and ubiquitylation by pVHL. Sci Signal 2: ra33, 2009.

36. Luo W, Hu H, Chang R, Zhong J, Knabel M, O'Meally R, Cole RN, Pandey A and Semenza GL: Pyruvate kinase M2 is a PHD3-stimulated coactivator for hypoxia-inducible factor 1 . Cell 145: 732-744, 2011

37. Xue J, Li X, Jiao S, Wei Y, Wu G and Fang J: Prolyl hydroxylase-3 is down-regulated in colorectal cancer cells and inhibits IK Kbeta independent of hydroxylase activity. Gastroenterology 138: 606-615, 2010 